\title{
SISTEM INFORMASI PARIWISATA SEBAGAI MEDIA PROMOSI PADA DINAS KEBUDAYAAN DAN PARIWISATA KOTA TIDORE KEPULAUAN
}

\section{TOURISM INFORMATION SYSTEM AS A MEDIA PROMOTION IN DEPARTMENT CULTURE AND TOURISM TIDORE ISLANDS CITY}

\author{
Hairil Kurniadi Siradjuddin \\ Program Studi Teknik Informatika \\ Fakultas Teknik, Universitas Khairun Ternate \\ hairil.kurniadi@unkhair.ac.id
}

\begin{abstract}
Abstrak
Untuk mengetahui potensi wisata diperlukan system computer untuk membangun dan merancang sebuah system informasi pariwisata yang terintergrasi kedalam sebuah database berbasis web programming. Penelitian dilakukan pada Dinas Kebudayaan dan Pariwisata Kota Tidore Kepulauan, Metode yang digunakan dalam penelititan ini adalah menggunakan metode waterfall yang merupakan bagian dari SDLC (siklus hidup system) yang memiliki beberapa tahapan dalam pembangunan system, Teknik dalam pengumpulan data yaitu dengan cara studi pustaka dan literature, metode studi pustaka digunakan untuk pencarian dan pengumpulan data, software recruitment yang digunakan seperti, macromedia dreamwaver, PHP MySQL, Local Server serta hardware yang kompatibel dalam menunjang pembuatan sistem informasi promosi pariwisata. Hasil yang diharapkan adalah dengan adanya system informasi pariwisata ini dapat membantu promosi dan pengenalan tentang pariwisata di Kota Tidore Kepulauan, referensi belajar untuk pelajar dan mahasiswa serta pusat data bagi instansi yang terkait dengan pariwisata. Kesimpulannya adalah dengan adanya sistem informasi pariwisata berbasis web ini dapat membuka akses dan jaringan didaerah agar lebih dikenal secara nasional maupun internasional.
\end{abstract}

Kata Kunci : Sistem Informasi, Pariwisata, Kota Tidore Kepulauan

\begin{abstract}
To find out tourism potential, a computer system is needed to build and design an integrated tourism information system into a web programming based database. The study was conducted at the Tidore Islands Culture and Tourism Office, The method used in this study is to use the waterfall method which is part of the SDLC (system life cycle) which has several stages in system development, Techniques in data collection are by way of literature and literature study, Literature study method is used for searching and collecting data, recruitment software used Macromedia Dreamweaver, PHP MySQL, Local Server and compatible hardware to support the creation of tourism promotion information systems. The expected result is that with this tourism information system can help the promotion and introduction of tourism in the City of Tidore Islands, learning references for students and students as well as data centers for agencies related to tourism. The conclusion is that with
\end{abstract}


this web-based tourism information system can open access and regional networks to be better known nationally and internationally.

\section{Keywords: Information system of culture and tourism, Tidore Island City}

\section{PENDAHULUAN}

Perkembangan teknologi informasi yang sangat cepat dewasa ini sangat mempengaruhi aktivitas atau kegiatan manusia,diantara pengaruh perkembangan teknologi tersebut yaitu penggunaan teknologi informasi dalam menyelesaikan masalah-masalah kehidupan manusia diberbagai aspek, seperti aspek pendidikan, industry, perttanian, agri bisnis, militer, publikasi dan promosi.

Pemanfaatan teknologi informasi di bidang publikasi dan promosi dapat dijadikan alat bantu untuk menciptakan media promosi, diantaranya penggunaan media internet sebagai alat publikasi atau penawaran suatu produk kepada khalayak ramai yang tidak dibatasi oleh ruang dan waktu.

Kota Tidore Kepulauan sebagai salah satu tujuan dari kunjungan wisata secara tidak langsung ikut terpengaruh dengan kemajuan teknologi tersebut. Kota ini memiliki luas wilayah $9.564,7 \mathrm{~km}^{2}$ dan berpenduduk sebanyak 98.025 jiwa (2010). Beberapa objek wisata yang ada di kota ini adalah pantai Ake Sahu, taman laut Pulau Maitara, (Tanjung Tongowai), museum Kesultanan Tidore Sonyine Malige, pantai Cobo, benteng Tahua dan tugu pendaratan "Sebastiano De Elcano" (pelaut dari Spanyol).

Kurangnya sarana dan prasarana berbasis teknologi merupakan faktor penyebab terhambatnya kemajuan serta kesulitan untuk mendapatkan informasi tentang suatu daerah dalam hal ini adalah kebudayaan yang merupakan modal bagi pengembangan pariwisata, untuk lebih jelasnya dapat disampaikan beberapa permasalahan yang terjadi di Kota Tidore yang berkaitan dengan perkembangan serta kemajuan dan peningkatan kunjungan wisata didaerah :

a. Belum adanya media atau akses internet didaerah segingga menyulitkan bagi masyarakat yang ingin mencari informasi dan berkunjung ke kota Tidore.

b. Data dan dokumen yang berhubungan dengan pariwisata masih dikelola dengan cara manual serta belum terhimpun dalam sebuah database.

c. Belum adanya situs yang berisi tentang pariwisata didaerah

d. Sering terjadinya pengklaiman terhadap budaya daerah yang merupakan potensi besar dari pariwisata.

e. Letak geografis bangsa Indonesia yang terlalu luas sehingga mengakibatkan kurangnya kontrol dari pemerintah pusat.

Pemanfaatan teknologi informasi pariwisata yang berbasis luas dan besar untuk memperkenalkan karakteristik budaya suatu daerah keseluruh pelosok Indonesia bahkan internasional dengan menggunakan teknologi berbasis internet (web database Programming) sehingga seluruh informasi yang menyangkut pariwisata disuatu daerah dapat terhimpun atau terpusat dalam sebuah database,dan memudahkan bagi (user), pengunjung maupun pelajar/mahasiswa untuk memanfaatkan system informasi tersebut.

Berdasarkan permasalahan tersebut diatas maka perlu adanya pembangunan Sistem Informasi Pariwisata Sebagai 
Media Promosi pada Dinas Kebudayaan Dan Pariwisata Kota Tidore Kepulauan", agar dapat membantu pemerintah dalam mempromosikan informasi wisata diKota Tidore Kepulauan

\section{Rumusan Masalah}

Bagaimana merancang sebuah system yang bisa mengolah Data, informasi dan dokumen tentang pariwisata dengan cepat.dan akurat. Agar dapat membantu pemerintah dalam mempromosikan informasi wisata di Kota Tidore Kepulauan

\section{LANDASAN TEORI}

\section{Pengertian sistem}

Pengertian sistem menurut Romney dan Steinbart (2015:3) Sistem adalah rangkaian dari dua atau lebih komponenkomponen yang saling berhubungan, yang berinteraksi untuk mencapai suatu tujuan. Sebagian besar sistem terdiridari subsistem yang lebih kecil yang mendukung sistem yang lebih besar.

Pengertian sistem menurut Anastasia Diana \& Lilis Setiawati (2011:3), Sistem merupakan "serangkaian bagian yang saling tergantung dan bekerja sama untuk mencapai tujuan tertentu".

\section{Pengertian informasi}

Menurut Romney dan Steinbart (2015:4) Informasi (information) adalah data yang telah dikelola dan diproses untuk memberikan arti dan memperbaiki proses pengambilan keputusan. Sebagaimana perannya, pengguna membuat keputusan yang lebih baik sebagai kuantitas dan kualitas dari peningkatan informasi.

\section{Pengertian Sistem Informasi}

Menurut Krismaji (2015:15) Sistem informasi adalah cara-cara yang diorganisasi untuk mengumpulkan, memasukkan, dan mengolah serta menyimpan data, dan cara-cara yang diorganisasi untuk menyimpan, mengelola, mengendalikan, dan melaporkan informasi sedemikian rupa sehingga sebuah organisasi dapat mencapai tujuan yang telah ditetapkan

\section{Pengertian Pariwisata}

Menurut Prof. Salah Wahab dalam Oka A Yoeti (1994; 116.). Pariwisata adalah suatu aktivitas manusia yang dilakukan secara sadar yang mendapat pelayanan secara bergantian diantara orang-orang dalam suatu Negara itu sendiri/ diluar negeri, meliputi pendiaman orang-orang dari daerah lain untuk sementara waktu mencari kepuasan yang beraneka ragam dan berbeda dengan apa yang dialaminya, dimana ia memperoleh pekerjaan tetap.

\section{Pengertian Promosi}

Promosi menurut Dharmesta (2008;349), menyatakan: promosi adalah arus informasi atau persuasi satu arah yang dibuat untuk mengarahkan seseorang atau organisasi kepada tindakan yang menciptakan pertukaran dalam pemasaran

Menurut Buchari Alma (2007;179) Promosi yaitu adalah sejenis komunikasi yang memberikan penjelasan yang meyakinkan calon konsumen tentang barang dan jasa.

\section{Pengertian Web}

Menurut Rafi'I (2008:2) menjelaskan, "Web adalah suatu ruang informasi dimana sumber-sumber informasi dalam bentuk halaman-halaman baik teks, gambar, suara, dan video bahkan 
dilengkapi juga dengan link untuk menghubungkan dengan halaman lain, dapat diidentifikasi oleh pengenal global yang disebut Uniform Resource Identifier (URL)".

\section{MySQL}

Menurut Buana (2014:2), "MySQL Merupakan database server yang paling sering digunakan dalam pemograman PHP. MySQL digunakan untuk menyimpan data dalam database dan memanipulasi data-data yang diperlukan. Manipulasi data tersebut berupa menambah, mengubah, dan menghapus data yang berada dalam database".

\section{Macromedia Dreamwaver 8}

Macromedia Dreamweaver 8 atau yang disebut "Dreamweaver 8" adalah sebuah perangkat lunak aplikasi untuk mendesain dan membuat halaman web, anda tidak perlu lagi mengetik kode-kode HTML atau kode - kode lainnya. Selain HTML, Dreamweaver 8 juga mendukung CSS, JavaScript,PHP, ASP dan bahasa pemrograman lainnya. Dreamweaver 8 adalah versi terbaru dari Dreamweaver. Versi pertamanya sendiri diluncurkan sekitar tahun 1994 oleh Macromedia Inc. Dalam versi terbaru ini, banyak sekali fasilitas baru yang ditambahkan. Dreamweaver 8 juga menyediakan beberapa template halaman web terbaru, termasuk fasilitas Starter Pages (Arief Ramadhan;2007:2).

\section{PHP My Admin}

Menurut Nugroho (2013), "phpMyAdmin adalah tools yang dapat digunakan dengan mudah untuk memanajemen database MySQL secara visual dan Server MySQ1, sehingga kita tidak perlu lagi harus menulis query SQL setiap akan melakukan perintah operasi database". Tools ini cukup populer, Anda dapat mendapatkan fasilitas ini ketika menginstal paket triad phpMyAdmin, karena termasuk dalam xampp yang sudah di instal.

\section{XAMPP}

Menurut Buana (2014:4), “XAMPP adalah perangkat lunak opensource yang diunggah secara geratis dan bisa dijalankan di semua semua operasi seperti windows, linux, solaris, dan mac"

Menurut Nugroho (2013), di dalam folder utama xampp, terdapat beberapa folder penting yang perlu diketahui. Untuk lebih memahami setiap fungsinya, Anda dapat melihat penjelasannya sebagai berikut:

\begin{tabular}{|l|l|}
\hline Folder. & Keterangan \\
\hline Apache & $\begin{array}{l}\text { Folder utama dari } \\
\text { Apache Webserver }\end{array}$ \\
\hline Htdocs & $\begin{array}{l}\text { Folder utama untuk } \\
\text { menyimpan data- } \\
\text { data latihan web, } \\
\text { baik PHP maupun } \\
\text { HTML biasa }\end{array}$ \\
\hline Manual & $\begin{array}{l}\text { Berisi subfolder } \\
\text { yang di dalamnya } \\
\text { terdapat manual } \\
\text { program dan } \\
\text { database, termasuk } \\
\text { manual PHP dan } \\
\text { MySQL }\end{array}$ \\
\hline MySQL & $\begin{array}{l}\text { Folder utama untuk } \\
\text { database MySQL } \\
\text { Server. PHP Folder } \\
\text { utama untuk } \\
\text { program PHP }\end{array}$ \\
\hline
\end{tabular}

Sumber: Nugroho 2013 


\section{METODE PENELITIAN}

\section{Teknik Pengumpulan Data}

1. Studi Literatur.

Teknik Studi Literatur (Pustaka) dilakukan dengan kegiatan penghimpunan data, keterangan dan informasi dengan cara mempelajari, mendalami, menelaah dan mengutip teori-teori atau konsep secara cermat atas berbagai dokumen, arsip, hasil laporan, buku-buku ilmiah, persatuan perundang-undangan dan bahan-bahan tertulis lainnya yang relevan dengan variable atau topic judul penelitian.

2. Penelitian Lapangan

Dalam penelitian lapangan ini dilaksanakan pengamatan langsung terhadap objek penelitian yaitu dengan melalui:

3. Wawancara

Wawancara yaitu suatu teknik pengumpulan data dengan cara mengadakan tanya jawab langsung kepada responden dengan menggunakan wawancara terstruktur yang disiapkan oleh penulis.

4. Dokumentasi.

Pada teknik ini peneliti melakukan pengumpulan data dan dokumen tertulis berupa gambar serta data-data visual yang bisa menjadi acuan dalam penelitian

\section{Analisa data dan Informasi}

Setelah melakukan proses observasi dan riset pustaka, maka data dan informasi yang didapatkan adalah sebagai berikut :

1. System informasi pariwisata di Dinas Kebudayaan dan Pariwisata masih dikelola secara manual.

2. Data dan dokumen di lapangan masih belum terpusat.

3. Masih kurangnya akses internet di Kota Tidore Kepulauan.
4. Belum adanya website yang menyediakan tentang Informasi Pariwisata Kota TIKEP.

5. System informasi berbasis web cocok untuk mengelola informasi secara online.

6. System informasi berbasis web cocok untuk media promosi Pariwisata Kota Tidore Kepuluan.

7. Target dari system informasi ini adalah pengunjung local maupun nasional.

8. Sebagai referensi dan media pembelajaran bagi pelajar dan mahasiswa.

dalam pengumpulan data ini dapat penulis simpulkan bahwa diperlukan sebuah tampilan website yang dinamis serta menyediakan informasi dalm berntuk teks dan visual agar pengunjung atau pengguna lebih mudah dalam mendapatkan informasi yang di inginkan

\section{Metodologi Pengembangan Sistem}

Metodologi pengembangan system yang gunakan adalah metode waterfall yang merupakan salah satu metode dari system development life cycle (SDLC), dimana ada beberapa fase yang harus dilalui dalam perancangan system.

a. Perencanaan

Pada tahapan ini terdapat beberapa hal yang dilakukan, yaitu: Permintaan untuk mempelajari system, yaitu dimana konsultan dalam hal ini mempelajari sistem lama yang sedang berjalan. Output yang dihasilkan dalam fase ini adalah konsultan mencoba memahami keinginan klien tentang sistem yang diinginkan oleh mereka.

Peninjauan awal,pada tahap ini konsultan melakukan peninjauan terhadap sistem yang sedang berjalan untuk mengetahui sistem tersebut. 
b. Analisis.

Pada tahapan analisis terdapat beberapa hal yang dilakukan,diantaranya: Mencari kembali masalah,dalam tahap ini konsultan menganalisa masalah yang ada pada sistem lama sebagai bahan analisa terhadap sistem yang akan dibuat. Output pada tahap ini adalah setelah melakukan analisa, konsultan mendapatkan masalah yang ada pada sistem lama.

Memahami sistem yang sedang berjalan,konsultan pada tahap ini diharuskan memahami sistem lama yang sedang berjalan untuk membuat sistem baru. Output yang dihasilkan adalah konsultan dapat memahami terhadap sistem yang sedang berjalan.

c. Desain

Dalam fase desain, terdapat beberapa hal yang harus dilakukan, diantaranya adalah: Desain logical, pada tahapan ini dibuat rancangan algoritma serta flowchart untuk sistem yang akan dibangun. Pada tahapan ini output yang dihasilkan adalah algoritma atau prosedur untuk perancangan sistem serta diagram alur sistem yang telah dibuat.

Desain system, pada tahap ini dilakukan perancangan proses bisnis atas sistem yang akan dibuat, selain itu juga dilakukan proses pemodelan menggunakan data flow diagram (DFD) untuk merancang alur dari sistem dan perancangan database menggunakan entity relationship diagram (ERD). Output yang didapat adalah proses bisnis atas sistem tersebut, alur sistem dengan DFD, dan juga rancangan database dengan ERD. d. Implementasi dan Testing.

Pada tahapan implementasi dimana rancangan yang dibuat mulai dijalankan untuk membangun sistem tersebut

e. Pemeliharaan ( Maintenance )

Tahapan maintenance atau pemeliharaan merupakan tahapan terakhir dari metodologi pengembangan sistem menggunakan model SDLC, pada tahapan ini aktifitas yang dilakukan adalah perawatan terhadap sistem yang sedang berjalan dan mengawasi terhadap kesalahankesalahan yang terjadi pada sistem yang berjalan.

\section{Alat dan Bahan yang digunakan}

Perangkat Keras, Spesifikasi perangkat keras sebagai berikut :

1. Processor Intel Pentium Core 2 Duo 2,00 GHz.

2. Memory $1 \mathrm{~GB}$

3. PCI VGA $512 \mathrm{MB}$

4. Harddisk $500 \mathrm{~GB}$

5. Perangkat Jaringan (Kabel UTP, Modem, dan lain-lain )

6. Mouse, keyboard, dan monitor.

Spesifikasi perangkat lunak (software) sebagai berikut :

1. Database server

2. PHP

3. OS Wiindows

4. XAMPP

5. Macromedia Dreamwaver

6. Macromedia Flash.

\section{Analisa Sistem yang Berjalan}

Permasalahan sistem yang terjadi pada Dinas Kebudayaan dan Pariwsata Kota Tidore Kepulauan menyangkut data dan informasi tentang pariwisata yang belum terhimpun dalam sebuah sistem yang baik,sehingga mengakibatkan sering 
terjadinya kesalahan tetntang informasi pariwisata, begitupun orang yang ingin mencari tahu tentang informasi pariwisata sangat kesulitan untuk mendapatkannya, dikarenakan pengolahannya masih manual serta datanya masih dalam bentuk dokumen-dokumen dan masih terpisah sehingga tidak ada akses yang jelas untuk mendapatkannya,apalagi bagi pengunjung yang berada diluar daerah.

Dokumen-dokumen yang ada dalam sistem informasi ini sebenarnya sudah tersedia di lapangan, hanya saja dokumen itu tidak terdata dengan baik sehingga pihak-pihak yang memerlukannya mengalami kesulitan dalam mendapatkan atau mencarinya kembali, sebagian besar dokumen yang menunjang sistem informasi ini didapat dari situs-situs pribadi yang hanya menjadi tambahan maupun pemanis disitus mereka dan dari buku-buku pariwisata, literature serta riset terhadap hal-hal yang terkait dengan pembuatan sistem informasi pariwisata.

\section{Perencanaan dan Konsep Usulan Sistem}

Sistem informasi pariwisata berbasis web yang kami bangun ini adalah sebagai solusi untuk menjawab permasalahan yang terjadi di Kota Tidore Kepulauan menyangkut data dan informasi tentang pariwisata yang belum terhimpun dalam sebuah sistem yang baik,sehingga mengakibatkan sering terjadinya kesalahan tetntang informasi pariwisata, begitupun orang yang ingin mencari tahu tentang informasi pariwisata sangat kesulitan untuk mendapatkannya,dikarenakan pengolahannya masih manual serta datanya masih dalam bentuk dokumendokumen dan masih terpisah sehingga tidak ada akses yang jelas untuk mendapatkannya, apalagi bagi pengunjung yang berada diluar daerah.
Oleh karena itu sistem informasi pariwisata berbasis web yang merupakan system komputerisasi yang mamanfaatkan jaringan internet adalah solusi yang tepat untuk memabangun sebuah system yang terpusat dalam sebuah database sehingga informasi bisa diterima dengan cepat, akurat serta efektif dan efesien,daripada menggunakan metode yang masih manual.

Sistem yang terkomputerisasi dan berbasis internet memiliki banyak keunggulan apalagi ditengah perkembangan teknologi yang sangat pesat, maka pembuatan sistem ini sangat diperlukan karena sistem computer memiliki keunggulan diantaranya adalah: Sistem dapat bekerja lebih cepat dan memiliki tingkat ketelitian yang sangat tinggi

\section{PERANCANGAN SISTEM}

\section{Perancangan Tabel Admin}

\begin{tabular}{|c|c|c|}
\hline \multicolumn{3}{|c|}{ Tabel admin } \\
\hline Nama Kolom & Tipe data & Ket \\
\hline Adm_id & $\operatorname{Varchar}(5)$ & \\
\hline $\begin{array}{c}\text { Adm_usernam } \\
\text { e }\end{array}$ & $\operatorname{varchar}(15)$ & \\
\hline $\begin{array}{c}\text { Adm_passwor } \\
\text { d }\end{array}$ & Varchar(12) & \\
\hline Adm_email & Varchar(15) & \\
\hline
\end{tabular}

\section{Perancangan Tabel Navigasi.}

\begin{tabular}{|c|c|c|}
\hline \multicolumn{3}{|c|}{ Tabel Navigasi } \\
\hline Nama Kolom & Tipe data & Ket \\
\hline Nav_id & $\operatorname{varchar}(6)$ & \\
\hline Nav_name & $\operatorname{varchar}(15)$ & \\
\hline
\end{tabular}

\section{Diagram Konteks}

Diagram konteks merupakan alat bantu dalam perancangan global bagi program aplikasi yang dibuat. Tujuannya adalah untuk mencerminkan keadaan sistem yang akan dibangun secara umum (Umagapi, Ambarita, A) 


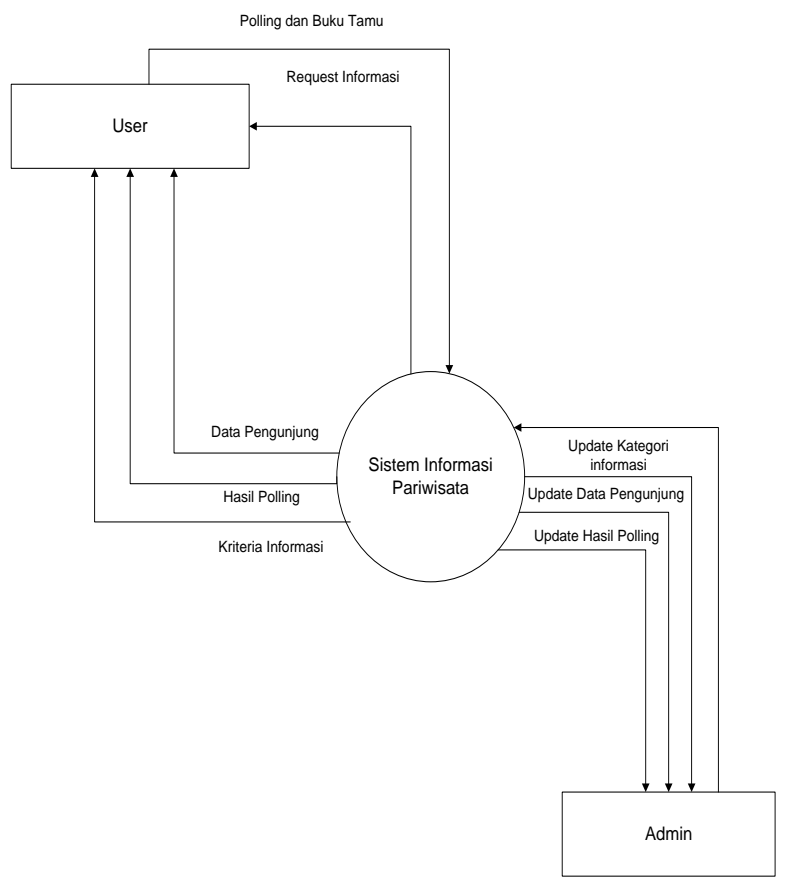

Gambar 1. Diagram Konteks

\section{DFD Level 0}

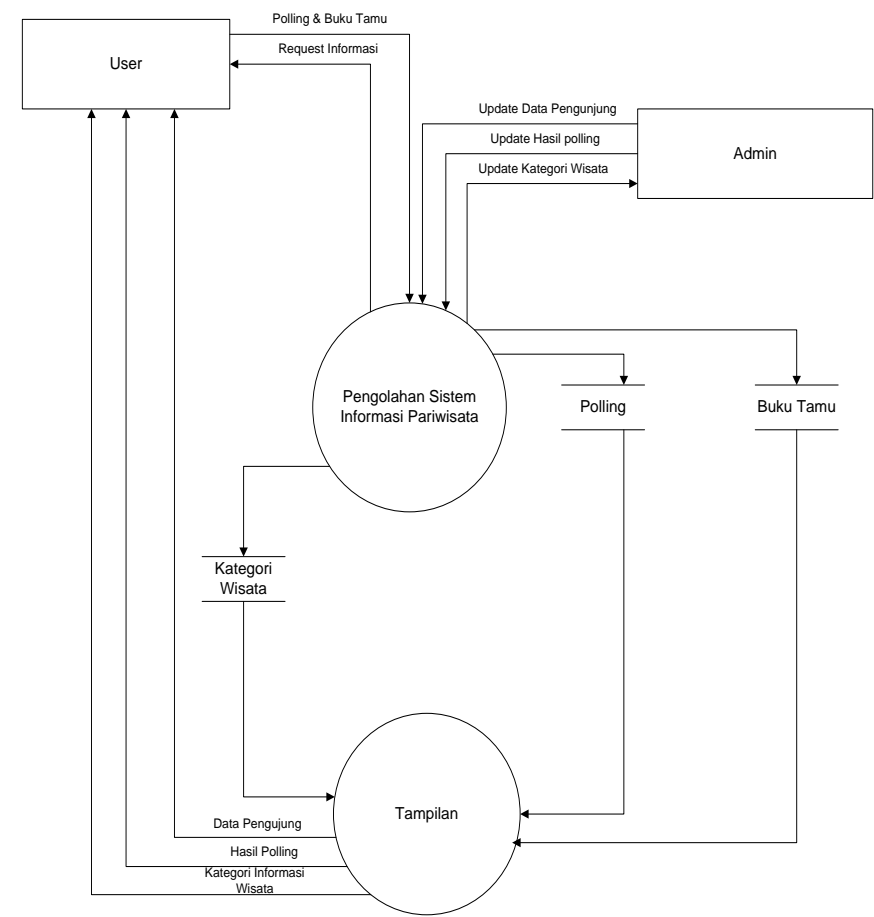

Gambar 2. Diagram Level 0

\section{Entity Relationship Diagram (ERD)}

Berikut merupaka diagram Entity Relationship Diagram yang ditampilkan pada gambar berikut:

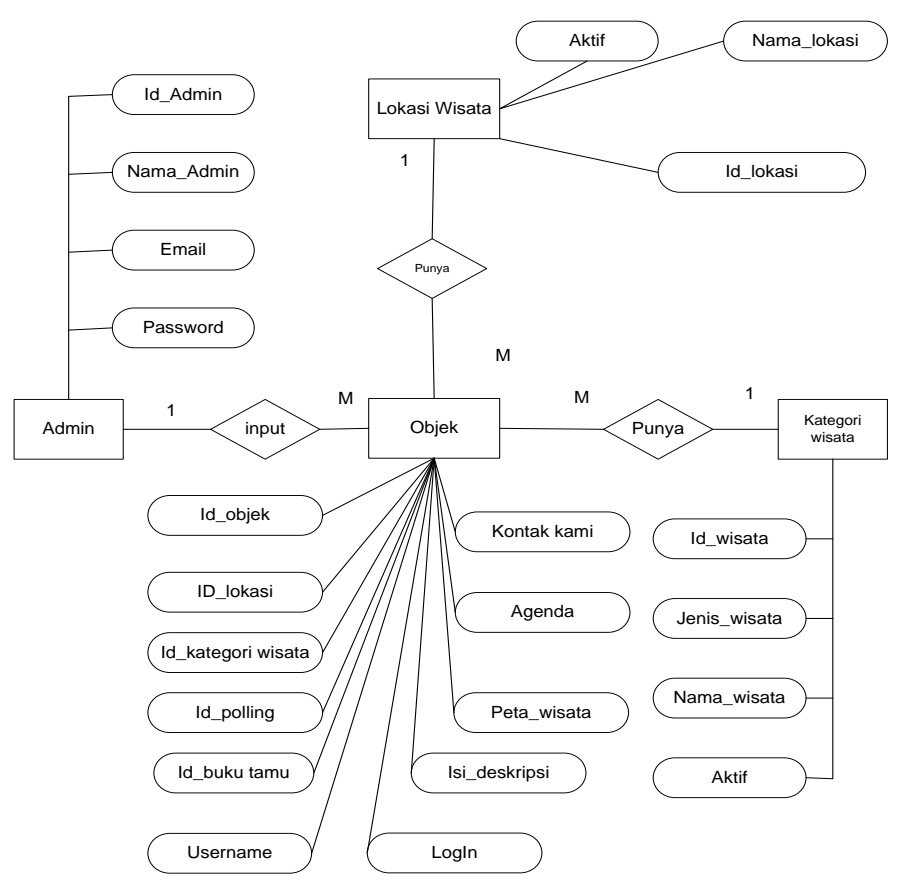

Gambar 3. Erd Sistem Promosi Pariwisata

\section{Perancangan Interface Sistem Desain Menu Utama}

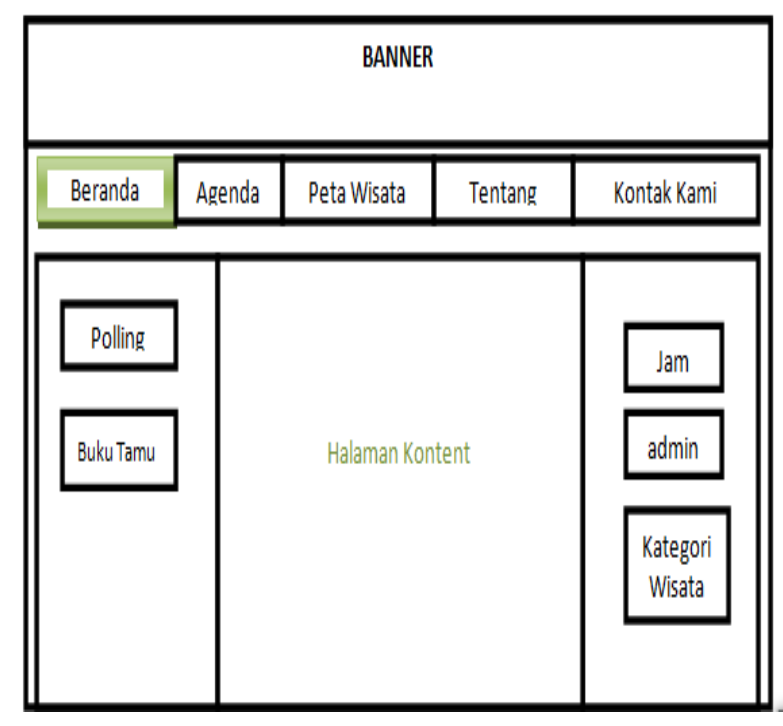

Gambar 4. Halaman Beranda Interface

\section{IMPLEMENTASI SISTEM}

Tahapan implementasi merupakan tahapan untuk menguji kelayakan suatu system informasi yang selanjutnya dioperasikan sesuai dengan fungsi dan kelayakannya. 


\section{Menu Utama}

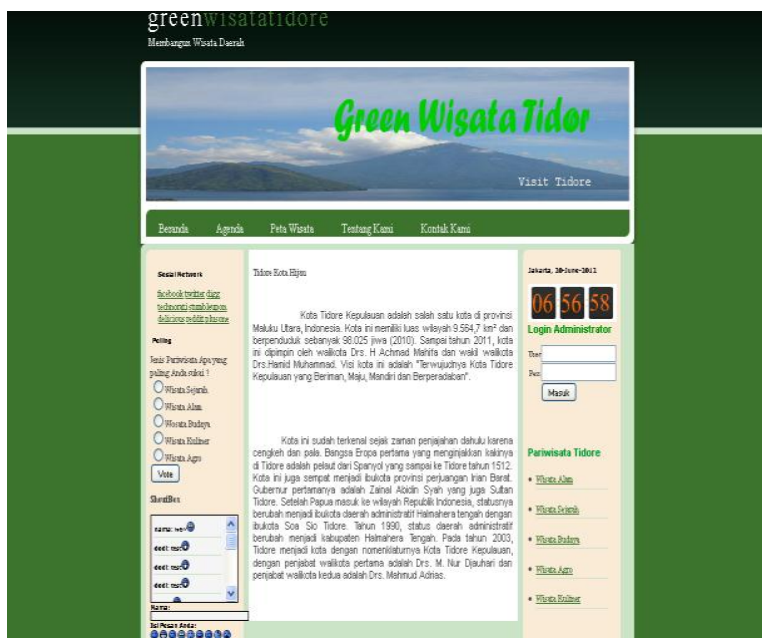

Gambar 5. Tampilan Menu utama

\section{Halaman Menu Agenda}

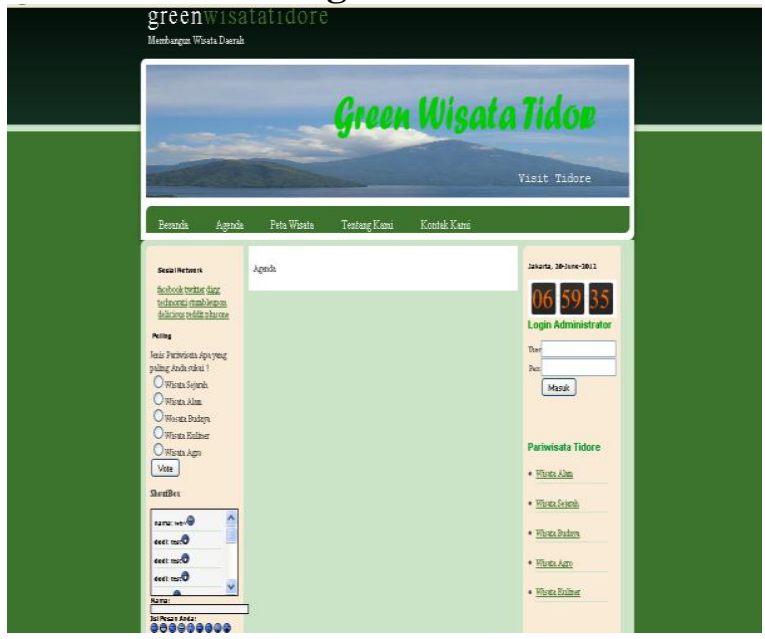

Gambar 6. Menu Agenda

\section{Halaman Menu Peta Wisata}

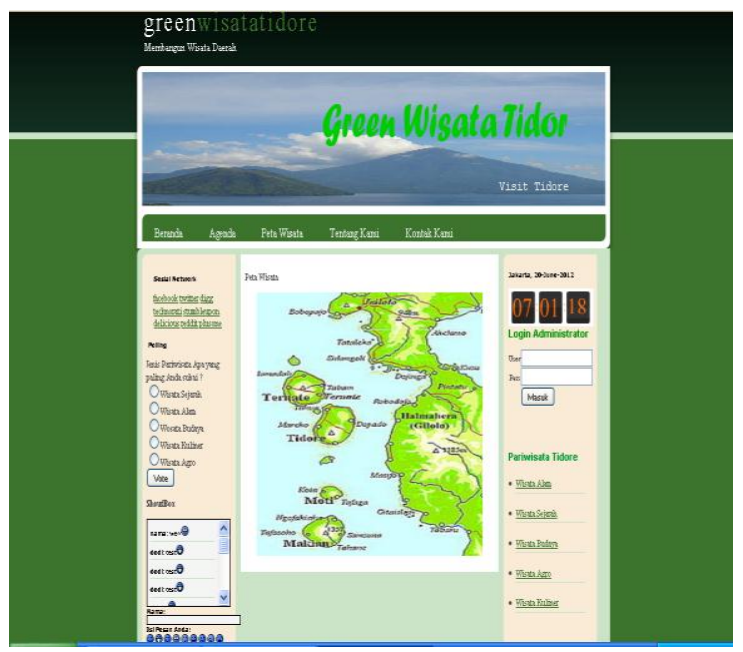

Gambar 7. Menu peta wisata
Halaman Menu Profil

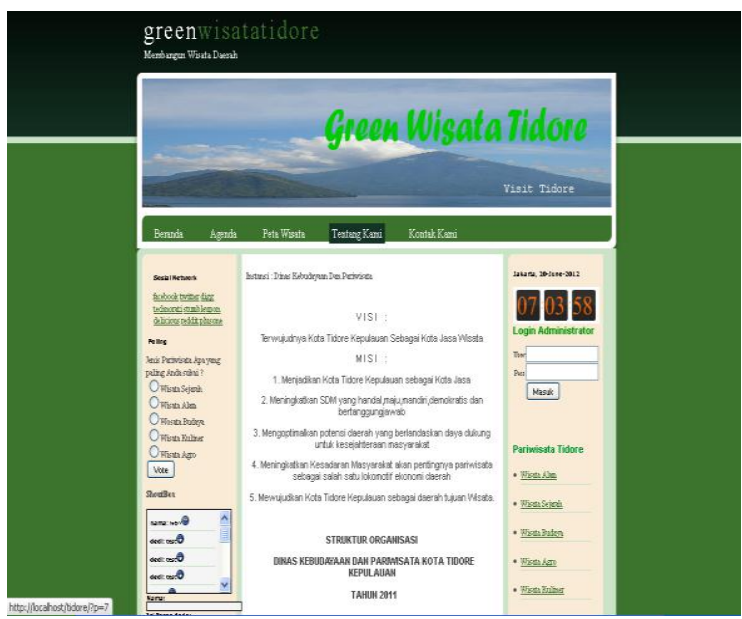

Gambar 8. Menu Profil

\section{Halaman Menu Admin}

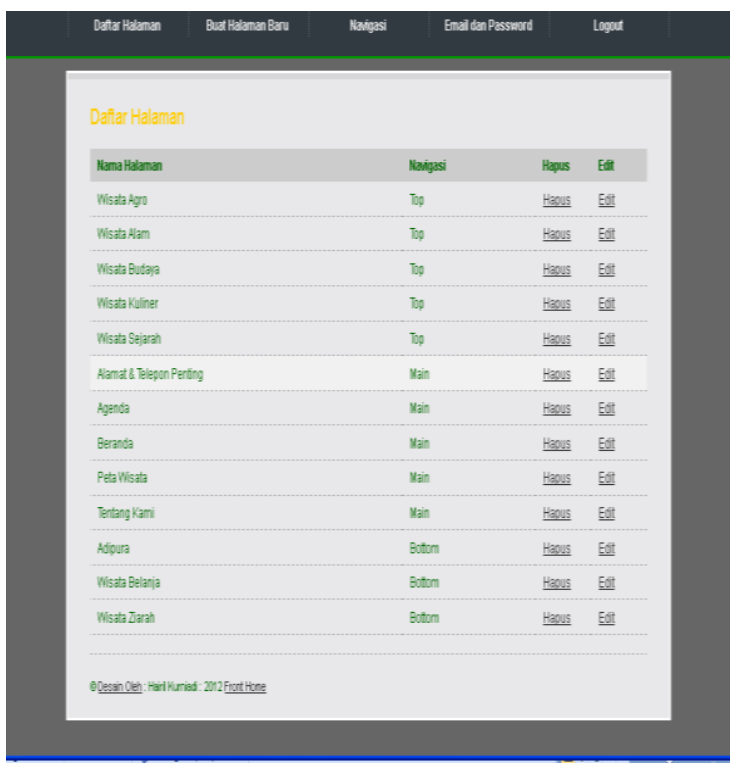

Gambar 9. Menu Admin

\section{Konsep Maintenance dan Pemeliharaan}

Tahap terakhir dari metode pengembangan system menggunakan Waterfall adalah pemeliharaan (maintenance system) ada beberapa hal yang harus diperhatikan dalam tahapan maintenance, diantaranya sebagai berikut:

\section{a. Maintenance aplikasi}

dimana pada proses ini dilakukan modifikasi software, perbaikan error atau umpan balik dari user terhadap software yang telah mereka gunakan.

\section{b. Maintenance Informasi}


yang dimaksudkan untuk keakuratan dan dinamisasi data serta informasi maka admin harus sering memperbaharui (update) isi dari content website tersebut,

c. Maintenance software dan hardware perlunya dilakukan pemeliharaan hardware dan software secara berkala untuk mengetahui kerusakan dan permsalahan yang dialami oleh perangkat tersebut.

\section{KESIMPULAN}

Berdasarkan hasil implementasi dan konsep pengembangan sistem pada Sistem Informasi Promosi Pariwisata pada Dinas Kebudayaan dan Pariwisata Kota Tidore Kepulauan maka dapat disimpulkan sebagai berikut. 1). Sistem Informasi ini dapat dijadikan sebagai media promosi diharapkan dapat memberikan informasi pariwisata serta untuk meningkatkan tingkat dan minat kunjungan wisatawan ke Kota TIKEP. 2). Pendistribusian program aplikasi ini sangat mudah, client hanya membutuhkan web browser saja karena program aplikasi ini berbasis web

Berdasarkan kesimpulan diatas maka dapat disarankan: 1). Upaya yang dilakukan untuk optimalisasi aplikasi diperlukan saran prasarana internet dan jaringan yang memadai. 2). Perlunya dilakukan sosialisasi menegenai manfaat dari aplikasi ini, melalui internet dan media massa, khususnya kepada wisatawan agar menjadi referensi bagi mereka yang akan berwisata,dan untuk kepentingan pendidikan bagi pelajar dan mahasiswa yang memerlukan informasi yang berkaitan dengan kurikulum pembelajaran
DAFTAR PUSTAKA

A Yoeti, Oka, 1996. Pengantar Ilmu Pariwisata, Edisi Revisi. Penerbit Angkasa: Bandung

Buchari Alma. 2007, Manajemen Pemasaran \& Pemasaran Jasa. CV.Alfabeta: Bandung

Ramadhan Arief, 2007, Student Guide Series: Macromedia Dreamweaver 8 , Elex Media Komputindo.

Basu Swasta, Dharmesta dan Irawan, 2008, Manajemen Pemasaran Modern, Liberty, Yogyakarta.

Rafi'i, Muhammad. 2008. Cara Cepat Membuat Website. Tiara Aksa: Surabaya

Anastasia Diana, Lilis Setiawati. 2011. Sistem Informasi Akuntansi, Perancangan, Prosedur dan Penerapan. Edisi 1. Andi: Yogyakarta Nugroho, Bunafit. 2013. Dasar Pemograman Web PHP - MySQL dengan Dreamweaver. Yogyakarta : Gava Media

Buana, I Komang Setia. 2014. Jago pemrograman PHP. Dunia Komputer: Jakarta

Romney, Marshal R. \& Paul John Steinbart, 2015. Sistem Informasi Akuntansi. Salemba Empat: Jakarta

Darman Umagapi, Arisandy Ambarita, Sistem Informasi Geografis Wisata Bahari pada Dinas Pariwisata Kota Ternate, Jurnal Ilmiah ILKOMINFO Jurnal Ilmu Komputer dan Informatika, Vol 1 No 2 Juli 2018, eISSN : 2621-4970, pISSN : 26214962 